\title{
Gambaran Pelaksanaan Sanitasi Total Berbasis Masyarakat (STBM) di Kelurahan Sri Padang Kecamatan Rambutan Kota Tebing Tinggi
}

\author{
Yunida Turisna Simanjuntak ${ }^{1, a}$, Eva Jusniar ${ }^{2, b}$ \\ ${ }^{1}$ Fakultas Farmasi Dan Ilmu Kesehatan, Universitas Sari Mutiara Indonesia, Medan 20123, Indonesia \\ ${ }^{2}$ Mahasiswa Fakultas Farmasi Dan Ilmu Kesehatan, Universitas Sari Mutiara Indonesia, Medan 20123, Indonesia \\ aturisna_yunida@yahoo.com*; b \\ *corresponding author
}

ARTICLE INFO

Keywords

Overview

STBM

$\mathrm{BABs}$

CTPS

PAMMRT

PSRT

PLCRT

\section{ABSTRACT}

STBM (Community Based-Total Sanitation) or Community Lead Total Sanitation (CLTS) in the government's program in strengthening the effort to develop healthy and clean life, preventing environment basedinfection, increasing people's capacity, and implementing government's commitment to increase the sustainable access to drinking water and basic sanitation in achieving Millennium Development Goals (MDGs).

The research used quantitative method with descriptive survey design which was aimed to find out the description of the implementation of STBM program at Kelurahan Sri Padang, Rambutan Sub-district, Tebing Tinggi. The population was 1,114 families at Kelurahan Sri Padang, and 92 of them were used as the samples, taken by using Slovin formula. The data were gathered by using primary and secondary data. The result of the research showed that of the 92 respondents, $26.1 \%$ of them were successful in stopping BABs and $73.9 \%$ of them were not, $19.6 \%$ of them washed their hands with soap well and $80.4 \%$ of them washed their hands with soap badly, 100\% of them had good drinking water and food processing, $100 \%$ of them had bad home waste processing, and $100 \%$ of them had bad sewage processing at Kelurahan Sri Padang, Rambutan Sub-district, Tebing Tinggi. It is recommended that the people at Kelurahan Sri Padang participate in STBM program so that healthy and clean life behavior can be changed and become sustainable at Kelurahan Sri Padang.

\section{Pendahuluan}

Sanitasi Total Berbasis Masyarakat (STBM) atau dikenal juga dengan nama Community Lead Total Sanitation (CLTS) merupakan program pemerintah dalamrangka memperkuat upaya pembudayaan hidup bersih dan sehat, mencegah penyebaran penyakit berbasis lingkungan, meningkatkan kemampuan masyarakat, serta mengimplementasikan komitmen pemerintah untuk meningkatkan akses air minum dan sanitasi dasar berkesinambungan dalam pencapaian Millenium Development Goals (MDGs) tahun 2015. Upaya sanitasi berdasarkan Peraturan Mentri Kesehatan RI Nomor 3 Tahun 2014 yang disebut Sanitasi Total Berbasis Masyarakat (STBM) yaitu meliputi Stop Buang Air Besar Sembarangan (SBS), Cuci Tangan Pakai Sabun, Pengelolaan Air Minum dan Makanan Rumah Tangga, Pengamanan Sampah Rumah Tangga, dan Pengamanan Limbah Cair Rumah Tangga [1]

Pelaksanaan program STBM dimulai dari pilar pertama yaitu Stop BABS yang merupakan pintu masuk sanitasi total dan merupakan upaya memutuskan rantai kontaminasi kotoran manusia terhadap air baku minum, makan dan lainnya. STBM menggunakan pendekatan yang mengubah perilaku hygiene dan sanitasi melalui pemberdayaan masyarakat dengan cara pemicuan. Dengan metode pemicuan, STBM diharapkan dapat merubah perilaku kelompok masyarakat dalam upaya memperbaiki keadaan sanitasi lingkungan mereka, sehingga tercapai kondisi Open Defecation Free 
(ODF), pada suatu komunitas atau desa. Suatu desa dikatakan ODF jika 100\% penduduk desa tersebut mempunyai akses $\mathrm{BAB}$ di jamban [2].

Data yang diperoleh dari Provinsi Sumatera Utara (2017), bahwa desa yang telah melaksanakan STBM sebanyak $1.942(31,77 \%)$ dari 6.112 desa/kelurahan yang ada di wilayah Provinsi Sumatera Utara. [3].

Berdasarkan hasil Survei Sosial Ekonomi Nasional (Susenas) 2017 yang diterbitkan BPS Provinsi Sumatera Utara, diketahui bahwa persentase terbesar rumah tangga berdasarkan sumber air minum adalah air isi ulang (32,24\%), diikuti penggunaan sumur bor/pompa sebesar 19,42\%, ledeng sebesar $14,12 \%$, sumur terlindungi $10,51 \%$, mata air terlindungi sebesar $8,27 \%$, air kemasan bermerek sebesar $3,51 \%$ serta masih terdapat $4,13 \%$ penduduk yang memperoleh air minumnya bersumber dari permukaan dan air hujan. Peningkatan akses rumah tangga terhadap sumber air minum yang sehat tentunya dapat menurunkan prevalensi kasus-kasus penyakit infeksi yang menular melalui air (water borned diseases) serta berdampak positif terhadap peningkatan status kesehatan masyarakat [3].

Kota Tebing Tinggi merupakan salah satu kota yang ada di Provinsi Sumatera Utara. Dari 160.686 penduduk yang ada di Kota Tebing Tinggi, hanya 45.417 (28,3\%) yang memiliki jamban yang sehat dan sebanyak 109.716 orang penduduk (68\%) yang menggunakan sarana air minum memenuhi syarat kesehatan [3].

Pendekatan STBM telah di laksanakan di wilayah kerja Dinas Kesehatan Kota Tebing Tinggi yaitu di Seluruh Cakupan Puskesmas Kota Tebing Tinggi. Dari 35 kelurahan yang ada di Kota Tebing Tinggi, hanya 34 kelurahan yang melaksanakan STBM $(97,1 \%)$. Dari 34 kelurahan yang melaksanakan STBM masih 15 kelurahan (43\%) yang masuk dalam kelurahan STBM dan 12 kelurahan (34\%) yang sudah Stop BABs (Profil Dinas Kesehatan Kota Tebing Tinggi, 2017). Sedangkan pada bulan November 2018, bertambah 1 kelurahan yang melaksanakan STBM dari 15 kelurahan menjadi 16 kelurahan [4]. Kondisi sanitasi dasar masyarakat di Kelurahan Sri Padang masih memprihatinkan. Masih ada masyarakat yang buang air besar sembarangan seperti di selokan, sungai, dan disembarang tempat lainnya. Hal ini tentu merupakan sumber penularan penyakit bagi masyarakat dan sangat mengganggu dari segi estetika akibat bau yang ditimbulkan, selain itu masih ditemukan rumah dan lingkungan sekitarnya yang tidak memenuhi syarat kesehatan, tidak ada saluran pembuangan air limbah.

Berdasarkan data yang diperoleh dari Puskesmas Sri Padang, bahwa pendekatan STBM telah di laksanakan pada tahun 2018. Pelaksanaan dari 2 kelurahan yang melaksanakan STBM, ditemukan perilaku masyarakat yang berhubungan dengan lima pilar STBM yaitu dari $2.436 \mathrm{KK}$ yang ada di wilayah kerja Puskesma Sri Padang, terdapat 212 KK $(8,7 \%)$ yang masih melakukan buang air besar sembarangan, sebanyak 342 KK (14\%) yang menggunakan sarana air minum belum memenuhi syarat kesehatan, terdapat $1.826(74,9 \%)$ yang sudah membiasakan untuk melakukan cuci tangan pakai sabun, terdapat $1.231 \mathrm{KK}(50,5 \%)$ yang tidak membuang sampah sembarangan dan $1.458 \mathrm{KK}(59,8 \%)$ membuang limbah cair rumah tangga sesuai dengan syarat kesehatan (memenuhi syarat kesehatan). Adapun kelurahan yang masih melakukan buang air besar sembarangan terbanyak adalah Kelurahan Sri Padang yaitu 191 KK $(16,7 \%)$ dari 1.144 KK yang ada. Di kelurahan Sri Padang ini terdapat sebuah sungai yakni Sungai Padang dan mayoritas penduduk yang tinggal dipinggiran sungai tersebut masih melakukan aktifitas pembuangan akhir seperti limbah rumah tangga, BABs di sungai, sampah dibuang ke sungai dan lain-lain.

Kondisi ini selanjutnya menimbulkan implikasi serius terhadap kualitas sumber daya manusia dan kemampuan produktif suatu bangsa dimasa yang akan datang. Baik secara langsung maupun tidak langsung, kebiasaan ini mengakibatkan sumber air minum terkontaminasi serta pencemaran yang terjadi berulang kali pada sumber air bahkan makanan yang disantap di rumah warga. BABS merupakan satu dari sekian banyak alasan mengapa penyakit seperti diare dan cacingan. Tidak hanya itu, balita pun mudah terserang pneumonia akibat terpapar udara yang telah tercemar oleh feses manusia. Bakteri yang penyebab penyakit yang paling sering ditemukan akibat buang air besar sembarangan ke sungai adalah Escherichia coli. Itu merupakan bakteri penyebab diare. Diare dapat menyebabkan kematian akibat dehidrasi. Penyakit perilaku $\mathrm{BAB}$ sembarangan juga memperbesar risiko yang menghambat pertumbuhan fisik anakanak. 
Pemicuan STBM yang dilaksanakan oleh Dinas Kesehatan \& Puskesmas Sri Padang di Kelurahan Sri Padang masih diutamakan pada pilar pertama yaitu Stop Buang Air Besar Sembarangan (SBS), tetapi pada penelitian skripsi ini peneliti juga membahas empat pilar lainnya yaitu Cuci Tangan Pakai Sabun, Pengelolaan Air Minum dan Makanan Rumah Tangga, Pengamanan Sampah Rumah Tangga serta Pengamanan Limbah Cair Rumah Tangga. Pemantauan lima pilar ini diharapkan dapat mengetahui pencapaian keberhasilan Program STBM di masyarakat. Berdasarkan latar belakang di atas, maka penulis tertarik untuk melakukan penelitian dengan judul "Gambaran Pelaksanaan Sanitasi Total Berbasis Masyarakat (STBM) di Kelurahan Sri Padang Kecamatan Rambutan Kota Tebing Tinggi Tahun 2019”.

\section{Metode}

Penelitian ini adalah penelitian kuantitatif dengan jenis penelitian survei deskriptif untuk mengetahui gambaran pelaksanaan programSTBM di Kelurahan Sri Padang Kecamatan Rambutan Kota Tebing Tinggi tahun 2019. Populasi penelitian ini adalah seluruh kepala keluarga yang ada di kelurahan Sri Padang Kecamatan Rambutan Kota Tebing Tinggi sebanyak 1144 KK dan metode pengambilan sampel secara acak (random sampling) dan jumlah sampel diambil dengan menggunakan rumus Slovin dengan jumlah sampel adalah $92 \mathrm{KK}$.

Analisa data dilakukan dengan cara analisa univariat. Analisa univariatdilakukan untuk memperoleh gambaran setiap variabel yang diteliti baik variabel dependen maupun variabel independen. Dengan melihat distribusi frekuensi dapat diketahui deskripsi masing-masing variabel dalam penelitian.

\section{Hasil dan Diskusi}

\section{Deskripsi Stop Buang Air Besar Sembarangan}

Berdasarkan jawaban responden tentang pertanyaan pelaksanaan program stop buang air besar sembarangan (BABs) di Kelurahan Sri Padang, hasil pelaksanaan program tersebut dapat di lihat pada tabel berikut ini.

1. Distribusi Responden Tentang Stop BABs di Kelurahan Sri Padang Kecamatan Rambutan Kota Tebing Tinggi Tahun 2019

\begin{tabular}{lrc}
\hline Pertanyaan & Jumlah (n) & $\%$ \\
\hline 1. Terdapat kloset di dalam atau diluar rumah & & \\
\hline a. Ya & 57 & 94,6 \\
\hline b. Tidak & 92 & 100 \\
\hline Total & & \\
\hline $\begin{array}{l}\text { 2. Kloset berupa leher angsa atau lubang kloset } \\
\text { memiliki tutup agar serangga tidak bisa } \\
\text { menyentuh tinja }\end{array}$ & 87 & 94,6 \\
\hline a. Ya & 5 & 5,4 \\
\hline b. Tidak & 92 & 100 \\
\hline Total & & \\
\hline 3. Jarak pembuangan tinja ke sumur gali >10m. & 32 & 34,8 \\
\hline a. Ya & 60 & 65,2 \\
\hline b. Tidak & 92 & 100 \\
\hline Total & & \\
\hline 4. Tempat jongkok (kloset) terbuat dari bahan & 80 & 87 \\
yang kuat & 12 & 13 \\
\hline a. Ya & 92 & 100 \\
\hline b. Tidak & & \\
\hline$\quad$ Total & 82 & 89,1 \\
\hline 5. Tinja bayi dan lansia dibuang ke kloset & & \\
\hline a. Ya & & \\
\hline
\end{tabular}




\begin{tabular}{lcc}
\hline b. Tidak & 10 & 10,9 \\
\hline Total & 92 & 100 \\
\hline 6. Setiap orang dirumah menggunakan wc & & \\
\hline a. Ya & 24 & 26,1 \\
\hline b. Tidak & 68 & 73,9 \\
\hline$\quad$ Total & 92 & 100 \\
\hline $\begin{array}{l}\text { 7. Terdapat akses untuk membersihkan dubur (air } \\
\text { atau tisu) }\end{array}$ & & \\
\hline a. Ya & 85 & 92,4 \\
\hline b. Tidak & 7 & 7,6 \\
\hline Total & 92 & 100 \\
\hline $\begin{array}{l}\text { 8. Tidak terdapat tinja manusia terlihat di sekitar } \\
\text { rumah }\end{array}$ & & \\
\hline a. Ya & 92 & 100 \\
\hline b. Tidak & 0 & 0 \\
\hline Total & 92 & 100 \\
\hline
\end{tabular}

Berdasarkan uraian distribusi responden berdasarkan pertanyaan tentang stop buang air besar sembarangan di Kelurahan Sri Padang, maka secara keseluruhan dikategorikan menjadi dua kategori seperti yang terdapat di tabel berikut ini.

2. Deskripsi STBM Berdasarkan Stop BABs di Kelurahan Sri Padang Kecamatan Rambutan Kota Tebing Tinggi Tahun 2019

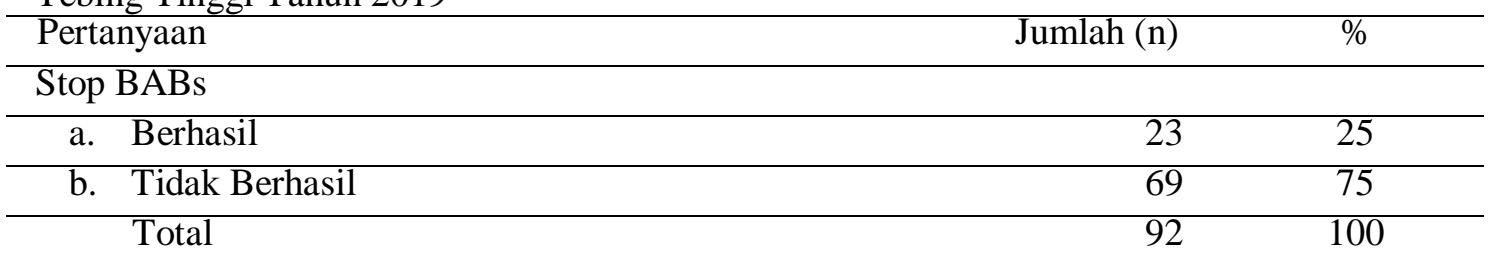

Berdasarkan tabel diatas menunjukan bahwa dari 92 responden, yang berhasil stop BABs sebanyak 23 KK (25\%) dan yang tidak berhasil sebanyak 69 KK (75\%).

Menurut Pedoman Pelaksanaan STBM tahun 2011, Indikator Pencapaian Stop Buang Air Besar Sembarangan terkait Jumlah dan Persentase Penduduk Tidak Buang Air Besar Sembarangan dengan indikator keberhasilan 100\% (Kemenkes, 2011). Dari hasil penelitian di ketahui bahwa pelaksanaan Pilar pertama STBM di Kelurahan Sri Padang mayoritas belum berhasil 75\%.

\section{Deskripsi Cuci Tangan Pakai Sabun (CTPS)}

Berdasarkan jawaban responden tentang pertanyaan pelaksanaan program cuci tangan pakai sabun (CTPS) di Kelurahan Sri Padang, hasil pelaksanaan program tersebut dapat di lihat pada tabel berikut ini.

3. Distribusi Responden Tentang CTPS di Kelurahan Sri Padang Kecamatan Rambutan Kota Tebing Tinggi Tahun 2019

\begin{tabular}{lrc}
\hline Pertanyaan & Jumlah (n) & $\%$ \\
\hline $\begin{array}{l}\text { 1. } \\
\text { Tersedia air mengalir di dalam rumah untuk } \\
\text { cuci tangan }\end{array}$ & & \\
\hline a. Ya & 19 & 20,7 \\
\hline b. Tidak & 73 & 79,3 \\
\hline Total & 92 & 100 \\
\hline Tersedia sabun untuk mencuci tangan & 92 & 100 \\
\hline a. Ya & 0 & 0 \\
\hline b. Tidak & &
\end{tabular}




\begin{tabular}{lrc}
\hline Total & 92 & 100 \\
\hline 3. & Ada perlengkapan CTPS di dalam rumah & \\
\hline a. Ya & 92 & 100 \\
\hline b. Tidak & 0 & 0 \\
\hline Total & 92 & 100 \\
\hline Setidaknya, setiap anggota keluarga tahu & & \\
saat-saat penting kapan mencuci tangan & 57 & 62 \\
a. Ya a & 35 & 38 \\
\hline b. Tidak & 92 & 100
\end{tabular}

Berdasarkan uraian distribusi responden berdasarkan pertanyaan tentang cuci tangan pakai sabun di Kelurahan Sri Padang, maka secara keseluruhan dikategorikan menjadi dua kategori seperti yang terdapat di tabel berikut ini.

4. Deskripsi STBM Berdasarkan Stop CTPS di Kelurahan Sri Padang Kecamatan Rambutan Kota Tebing Tinggi Tahun 2019

\begin{tabular}{|c|c|c|}
\hline Pertanyaan & Jumlah (n) & $\%$ \\
\hline \multicolumn{3}{|l|}{ CTPS } \\
\hline a. Baik & 18 & 19,6 \\
\hline b. Kurang Baik & 74 & 80,4 \\
\hline Total & 92 & 100 \\
\hline
\end{tabular}

Berdasarkan tabel diatas menunjukan bahwa cuci tangan pakai sabun yang baik sebanyak 18 KK $(19,6 \%)$ dan cuci tangan pakai sabun yang kurang baik sebanyak 74 KK $(80,4 \%)$.

Di ketahui dari hasil penelitian berdasarkan terdapat 74 responden $(80,4 \%)$ responden yang tidak berhasil menerapkan CTPS dengan kesadaran sendiri walaupun ada program CTPS di Kelurahan Sri Padang. Sehingga dalam Pedoman Pelaksanaan STBM tahun 2011, Indikator Pencapaian Cuci Tangan Pakai Sabun yaitu setiap anggota keluarga cuci tangan pakai sabun pada waktu-waktu kritis dengan indikator keberhasilan 100\% [6], sehingga pelaksanaan Pilar kedua STBM di Kelurahan Sri Padang tidak berhasil.

\section{Deskripsi PAM dan Makanan}

Berdasarkan jawaban responden tentang pertanyaan pelaksanaan program Pengelolaan air minum dan makanan rumah tangga di Kelurahan Sri Padang, hasil pelaksanaan program tersebut dapat di lihat pada tabel berikut ini.

5. Distribusi Responden Tentang PAM dan Makanan di Kelurahan Sri Padang Kecamatan Rambutan Kota Tebing Tinggi Tahun 2019

\begin{tabular}{lrc}
\hline Pertanyaan & Jumlah (n) & $\%$ \\
\hline 1. Selalu mengolah air sebelum diminum & & \\
\hline a. Ya & 92 & 100 \\
\hline b. Tidak & 0 & 0 \\
\hline$\quad$ Total & 92 & 100 \\
\hline $\begin{array}{l}\text { Air Minum yang telah diolah disimpan di } \\
\text { dalam wadah yang tertutup rapat }\end{array}$ & 92 & 100 \\
\hline a. Ya & 0 & 0 \\
\hline b. Tidak & 92 & 100 \\
\hline Total & & \\
\hline $\begin{array}{l}\text { Wadah minum dibersihkan secara rutin } \\
\text { (setidaknya seminggu sekali) }\end{array}$ & 92 & 100 \\
\hline a. Ya & 0 & 0 \\
\hline b. Tidak & &
\end{tabular}




\begin{tabular}{|c|c|c|}
\hline Total & 92 & 100 \\
\hline \multicolumn{3}{|l|}{ 4. Makanan yang tersaji tertutup } \\
\hline a. $\mathrm{Ya}$ & 92 & 100 \\
\hline b. Tidak & 0 & 0 \\
\hline Total & 92 & 100 \\
\hline \multicolumn{3}{|l|}{ 5. Wadah makanan selalu bersih } \\
\hline a. Ya & 92 & 100 \\
\hline b. Tidak & 0 & 0 \\
\hline Total & 92 & 100 \\
\hline
\end{tabular}

Berdasarkan uraian distribusi responden berdasarkan pertanyaan tentang pengelolaan air minum dan makanan rumah tangaa di Kelurahan Sri Padang, maka secara keseluruhan dikategorikan menjadi dua kategori seperti yang terdapat di tabel berikut ini.

6. Deskripsi STBM Berdasarkan PAM dan Makanan di Kelurahan Sri Padang Kecamatan Rambutan Kota Tebing Tinggi Tahun 2019

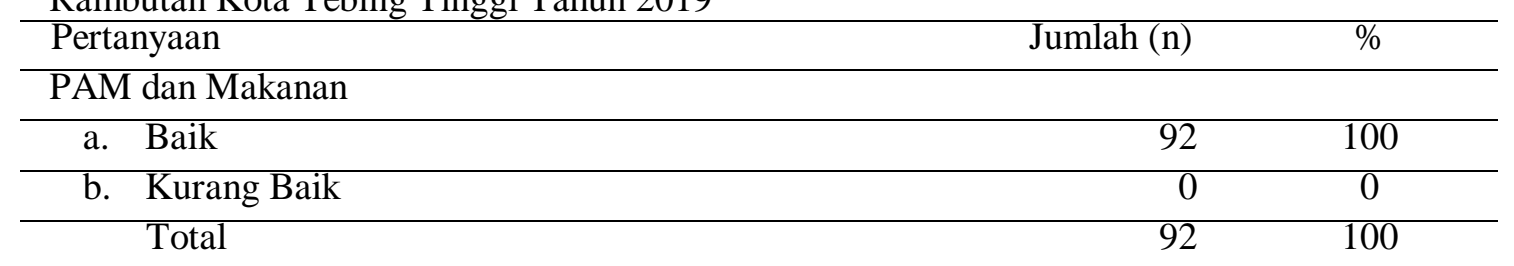

Berdasarkan tabel di atas menunjukan bahwa pengelolaan air minum dan makanan rumah tangga sebanyak 92 KK (100\%).

Diketahui hasil penelitian yaitu $100 \%$ responden melaksanakan pengelolaan air minum dan makanan dengan aman seperti yang di harapkan dalam Pedoman Pelaksanaan STBM tahun 2011, sehingga pelaksanaan pilar ketiga berhasil.

\section{Deskripsi Pengamanan Sampah Rumah Tangga (PSRT)}

Berdasarkan jawaban responden tentang pertanyaan pelaksanaan program pengamanan sampah rumah tangga (PSRT) di Kelurahan Sri Padang, hasil pelaksanaan program tersebut dapat di lihat pada tabel berikut ini.

7. Distribusi Responden Tentang PSRT di Kelurahan Sri Padang Kecamatan Rambutan Kota Tebing Tinggi Tahun 2019

\begin{tabular}{lrc}
\hline Pertanyaan & Jumlah (n) & $\%$ \\
\hline $\begin{array}{l}\text { 1. Sampah padat rumah tangga tidak dibuang } \\
\text { berserakan di halaman }\end{array}$ & & \\
\hline a. Ya & 9 & 9,8 \\
\hline b. Tidak & 83 & 90,2 \\
\hline Total perlakuan dengan aman terhadap & 92 & 100 \\
\hline $\begin{array}{l}\text { Ada pampah yang akan dibuang } \\
\text { a. Ya }\end{array}$ & & \\
\hline b. Tidak & 0 & 0 \\
\hline Total & 92 & 100 \\
\hline
\end{tabular}

Berdasarkan uraian distribusi responden berdasarkan pertanyaan tentang pengamanan sampah rumah tangga di Kelurahan Sri Padang, maka secara keseluruhan dikategorikan menjadi dua kategori seperti yang terdapat di tabel berikut ini.

8. Deskripsi STBM Berdasarkan PSRT di Kelurahan Sri Padang Kecamatan Rambutan Kota Tebing Tinggi Tahun 2019

\begin{tabular}{lll}
\hline Pertanyaan & Jumlah $(\mathrm{n})$ & $\%$ \\
\hline
\end{tabular}




\begin{tabular}{clcc}
\hline a. & Baik & 0 & 0 \\
\hline b. & Kurang Baik & 92 & 100 \\
\hline & Total & 92 & 100 \\
\hline
\end{tabular}

Berdasarkan tabel diatas menunjukan bahwa pengamanan sampah rumah tangga kurang baik sebanyak 92 KK (100\%).

Di ketahui bahwa yang menerapkan Pengamanan Sampah Rumah Tangga (PSRT) 92 responden $(100 \%)$ tidak melaksanakan pengamanan sampah rumah tangga. Menurut Pedoman Pelaksanaan STBM tahun 2011, Indikator Pencapaian Pengamanan Sampah Rumah Tangga yaitu Setiap Rumah tangga melakukan pengelolaan sampah dengan aman dengan indikator keberhasilan 100\% (Kemenkes, 2011), sehingga berdasarkan pedoman tersebut maka target pencapaian pilar keempat STBM di Kelurahan Sri Padang tidak berhasil.

\section{Deskripsi Pengamanan Limbah Cair Rumah Tangga (PLCRT)}

Berdasarkan jawaban responden tentang pertanyaan pelaksanaan program pengamanan limbah cair rumah tangga di Kelurahan Sri Padang, hasil pelaksanaan program tersebut dapat di lihat pada tabel berikut ini.

9. Distribusi Responden Tentang PLCRT di Kelurahan Sri Padang Kecamatan Rambutan Kota Tebing Tinggi Tahun 2019

\begin{tabular}{lcc}
\hline Pertanyaan & Jumlah (n) & $\%$ \\
\hline $\begin{array}{l}\text { 1. } \\
\text { kidak terlihat genangan air di sekitar rumah }\end{array}$ & & \\
a. Ya limbah domestic & 60 & 65,2 \\
\hline b. Tidak & 32 & 34,8 \\
\hline Total & 92 & 100 \\
\hline Limbah cair sudah diolah sebelum dibuang & & \\
\hline a. Ya & 0 & 0 \\
\hline b. Tidak & 92 & 100 \\
\hline Total & 92 & 100 \\
\hline
\end{tabular}

Berdasarkan uraian distribusi responden berdasarkan pertanyaan tentang pengamanan limbah cair rumah tangga di Kelurahan Sri Padang, maka secara keseluruhan dikategorikan menjadi dua kategori seperti yang terdapat di tabel berikut ini.

10.Deskripsi STBM Berdasarkan PLCRT di Kelurahan Sri Padang Kecamatan Rambutan Kota Tebing Tinggi Tahun 2019

\begin{tabular}{|c|c|c|}
\hline Pertanyaan & Jumlah (n) & $\%$ \\
\hline \multicolumn{3}{|l|}{ PLCRT } \\
\hline a. Baik & 0 & 0 \\
\hline b. Kurang baik & 92 & 100 \\
\hline Total & 92 & 100 \\
\hline
\end{tabular}

Berdasarkan tabel di atas menunjukan bahwa pengamanan limbah cair rumah tangga kurang baik sebanyak 92 KK (100\%).

Berdasarkan hasil penelitian bahwa 92 orang (100\%) tidak menerapkan Pengamanan Limbah Cair Rumah Tangga. Menurut Pedoman Pelaksanaan STBM tahun 2011, Indikator Pencapaian Pengamanan Limbah Cair Rumah Tangga terkait jumlah dan persentase rumah tangga mengelola limbah cairnya dengan aman yaitu dengan indikator keberhasilan 100\% (Kemenkes, 2011), sehingga berdasarkan pedoman tersebut maka pilar kelima tidak berhasil. 


\section{Kesimpulan}

1. Dari 92 responden, yang berhasil stop BABs sebanyak $26,1 \%$ responden dan yang tidak berhasil sebanyak $73,9 \%$ responden.

2. Cuci tangan pakai sabun yang baik sebanyak 19,6 responden dan kurang baik sebanyak $80,4 \%$ responden.

3. Pengelolaan air minum dan makanan rumah tangga yang baik sebanyak $100 \%$ responden.

4. Pengamanan sampah rumah tangga kurang baik sebanyak $100 \%$ responden.

5. Pengamanan limbah cair rumah tangga kurang baik sebanyak $100 \%$ responden.

\section{Saran}

1. Kepada Seksi Penyehatan Lingkungan, Makanan dan Minuman Dinas Kesehatan Tebing Tinggi di harapkan agar tetap memberikan informasi tentang Sanitasi Total Berbasis Masyarakat ( STBM ) dan juga agar mempertahankan kegiatan program STBM yang telah terlaksana yaitu Stop Buang Air Besar Sembarangan sehingga dapat mencapai indikator keberhasilan, serta di harapkan agar merencanakan pelaksanaan keempat pilar lainnya sehingga dapat tercapai keberhasilan dalam perubahan perilaku yang bersih dan sehat di Kelurahan Sri Padang.

2. Di harapkan kepada masyarakat Sri Padang agar ikut serta dalam program Sanitasi Total Berbasis Masyarakat, sehingga dapat terjadi perubahan dan kesinambungan perilaku yang bersih dan sehat di lingkungan masyarakat Sri Padang.

3. Diharapkan penelitian ini dapat bermanfaat untuk peneliti lainnya, agar penelitian lebih lanjut dapat menggali hal-hal lain yang mungkin dapat mempengaruhi perubahan perilaku yang berdasarkan STBM sehingga dapat tercipta lingkungan yang bersih dan sehat. Misalnya bekerja sama dengan lintas sektor dalam mempengaruhi sikap masyarakat akan pentingnnya STBM.

\section{Referensi}

[1] Arianti, 2013. Hubungan Antara Pengetahuan, Sikap, Dan Perilaku Ibu Mengenai Program Sanitasi Total Berbasis Masyarakat Terhadap Kejadian Diare pada Balita di Kelurahan Siantar Tengah. Naskah Publikasi. Program Studi Pendidikan Kedokteran. Fakultas Kedokteran Untan. http://www.google.com/urlvjurnal.untan.ac.id.Diakses tanggal 22 Maret 2019.

[2] Depkes RI. 2016. Strategi Nasional Sanitasi Total Berbasis Masyarakat. Jakarta.

[3] Dinas Kesehatan Provinsi Sumatera Utara. 2017. Profil Dinas Kesehatan Provinsi Sumatera Utara. Medan.

[4] Dinas Kesehatan Kota Tebing Tinggi. 2017. Profil Dinas Kesehatan Kota Tebing Tinggi. Tebing Tinggi.

[5] Gunawan, Indra, 2006. Pengetahuan Masyarakat Tentang Pengelolaan Sanitasi Berbasis Masyarakat. Tesis. Universitas Diponegoro Semarang.

[6] Hidayat. A.A. 2014. Metode Penelitian Kebidanan dan Teknik Analisis Data. Jakarta: Salemba Medika

[7] Kemenkes RI. 2014. Buku Saku Verifikasi STBM. Jakarta.

[8] Kemenkes RI. 2014. Pedoman Pelaksanaan Sanitasi Total Berbasis Masyarakat. Jakarta.

[9] Kemenkes RI. 2014. Peraturan Menteri Kesehatan Republik Indonesia Nomor 3 Tahun 2014 Tentang Sanitasi Total Berbasis Masyarakat. Jakarta

[10] Kemenkes RI. 2014. Kurikulum dan Modul Pelatihan Sanitasi Total Berbasis Masyarakat (STBM). Jakarta: Kementerian Kesehatan RI

[11] Kemenkes RI. 2015. Road Map Percepatan Program STBM 2013-2015: Kementerian Kesehatan RI

[12] Kemenkes RI, 2018. Profil Indonesia Tahun 2017. Jakarta: Katalog Dalam Terbitan

[13] Mubarak, Wahid Iqbal dan Nurul Chayatin, 2014. Ilmu Kesehatan Masyarakat Teori dan Aplikasi. Salemba Medika, Jakarta. 